\title{
Drosophila pericardial nephrocyte ultrastructure changes during ageing
}

\author{
Olympia-Ekaterini Psathaki ${ }^{\mathrm{a}, \mathrm{b}}$, Lena Dehnen ${ }^{\mathrm{a}}$, Paul Hartley ${ }^{\mathrm{c}}$, Achim Paululat ${ }^{\mathrm{a}, *}$ \\ ${ }^{a}$ University of Osnabrïck, Department of Zoology and Developmental Biology, Barbarastraße 11, 49076 Osnabrueck, Germany \\ ${ }^{\mathrm{b}}$ University of Osnabrück, Center of Cellular Nanoanalytics, Integrated Bioimaging Facility Osnabrück (iBiOs), Barbarastr. 11, 49076 Osnabrück, Germany \\ ${ }^{\mathrm{c}}$ University of Bournemouth, Department of Life and Environmental Science, Poole, Dorset BH12 5BB, UK
}

\section{ART ICLE INFO}

\section{Keywords:}

Renal system nephrology

Nephrocytes

Pericardial cells

Heart

Dorsalo vessel

Endocytosis

Ageing

Drosophila

Nephrocyte

Slit diaphragm

Ultrastructure

Pericardial cells

Heart

Autophagy

Endocytosis

Scavenger cells

Podocytes

\begin{abstract}
A B S T R A C T
Here we show that a labyrinth channel compartment and slit diaphragms, which are the histological structures enabling insect nephrocytes ultrafiltration, are established during embryogenesis first by the garland nephrocytes (GCNs). The later pericardial nephrocytes, which represent the majority of functional nephrocytes in larvae and adults, lack these characteristic features at the embryonic stage. During larval development, a subpopulation of the pericardial cells survives and matures into functional nephrocytes (PCNs) displaying a fully differentiated slit diaphragm and a labyrinth channel compartment. Likely the embryonic pericardial cells have primary functions other than ultrafiltration (e.g. in production and secretion of ECM constituents). We also show, for the first time, that PCNs in the adult fly undergo dramatic histological degeneration upon ageing. The slit diaphragms disappear, the labyrinth channel system degenerates and the lysosomal compartment becomes highly enriched with electron-dense material. When using nephrocytes as a model for genetic screening purposes or to investigate the specific role of genes involved in endocytosis, histological changes occurring upon ageing need to be taken into account when interpreting structural data.
\end{abstract}

\section{Introduction}

\subsection{The Drosophila renal system}

The haemolymph of insects circulates in the open body cavity with direct contact to tissues and organs and contains a heterogeneous mixture of nutrients, hormones, unwanted metabolites, free but unused or degraded ligands and matrix proteins released from intact or degraded extracellular matrix (ECM). Cells of the insects' immune system, the haemocytes, represent a substantial constituent of the haemolymph. Continuous movement of the haemolymph is achieved by the activity of the visceral and somatic muscles, which are directly suspended by the haemolymph, and by the pulsatory activity of the heart tube, which continuously pumps haemolymph from the posterior to the anterior (Lammers et al., 2017; Shahrestani et al., 2017). Additional pumping activity is provided by the accessory hearts (Pass et al., 2015), which represent specialised muscles ensuring haemolymph streaming in the antenna, wings or legs.

\footnotetext{
* Corresponding author.

Email address: paululat@biologie.uni-osnabrueck (A. Paululat)
}

However, important proteins delivered by the haemolymph flow include matrix proteins such as Collagen IV (viking) (Pastor-Pareja and $\mathrm{Xu}, 2011$ ) or Pericardin (Drechsler et al., 2013) and antimicrobial substances that act during parasite defence. Components present in the haemolymph are secreted by different cells including pericardial cells (Fife et al., 1987), midgut cells (Palli and Locke, 1987b), epidermal cells (Palli and Locke, 1987a) and fat body cells (Palli and Locke, 1988). Palli and Locke analysed the origin of 26 polypeptides present in the haemolymph of larva of the Lepidopteran Calpodes. Fourteen of the 26 proteins were synthesised and secreted by adipocytes, amounting to about $90 \%$ of the total haemolymph protein (Palli and Locke, 1988). Thus, the fat body cells represent the major source for secreted haemolymph proteins in general. A recent proteomic analysis of the fly haemolymph showed the presence of more than 500 different proteins and that the loss of nephrocytes led to an increased concentration of SPARC which finally lead to cardiomyopathy (Hartley et al., 2016). 
The haemolymph contains wanted and unwanted constituents, and a major task for the organism is the removal or recycling of the unwanted material. In insects, this task is achieved by two tissues, the nephrocytes and the Malpighian tubules, which constitute the excretion system of the fly. Two classes of nephrocytes filter haemolymph; they are the garland cell nephrocytes (GCNs) and the pericardial cell nephrocytes (PCNs; also known as pericardial cells) (Fig. 1). GCNs have been established as an important model for investigating endocytosis and nephrocyte filtration in insects (Aggarwal and King, 1967; Akbar et al., 2011; Koenig and Ikeda, 1990; Kosaka and Ikeda, 1983; Tutor et al., 2014; Weavers et al., 2009), for the expression and analysis of mammalian nephrocyte proteins (Helmstädter et al., 2012) and, in principle, as a highly versatile model for human nephrotic syndromes (Helmstädter and Simons, 2017; Hermle et al., 2017).

The second type of nephrocytes present in the Drosophila embryo are the pericardial nephrocytes (PCN) (Fig. 1A, C, E-J). About 110-130 mononucleated pericardial cells differentiate during embryogenesis (Albrecht et al., 2006; Ward and Skeath, 2000). During larval development a population of around 40-50 pericardial cells display enlarged nuclei and polytenisation (Kambysellis and Wheeler, 1972; Rizki, 1978). The majority of the embryonic pericardial

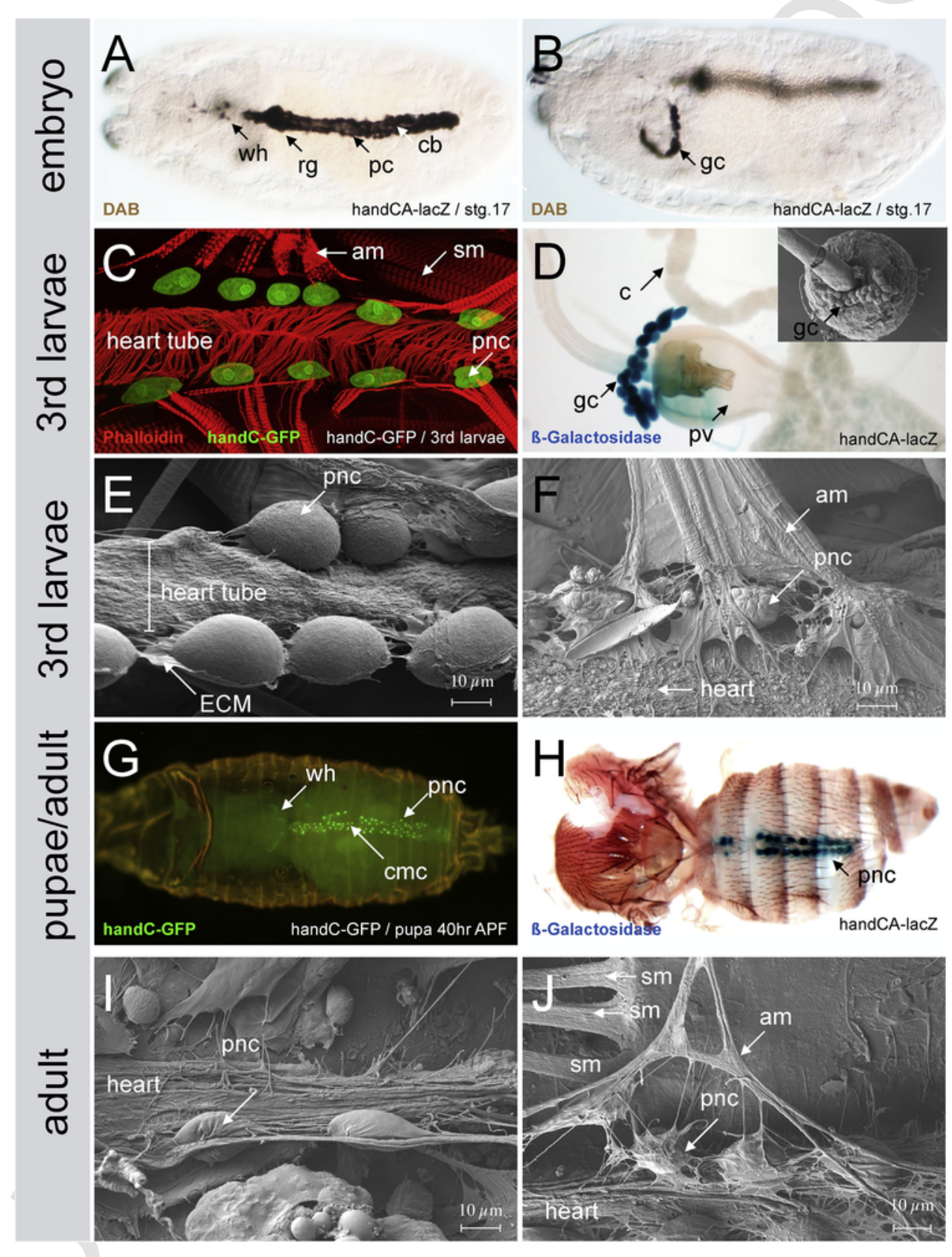

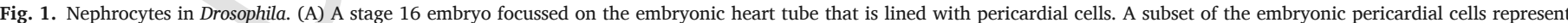

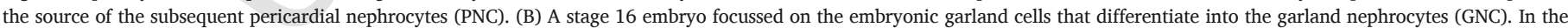

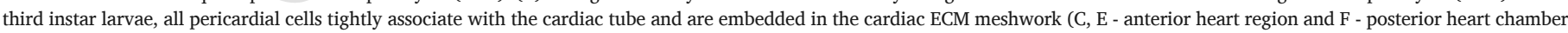

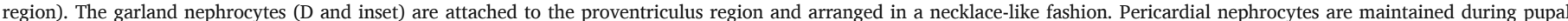

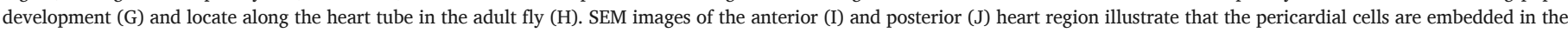

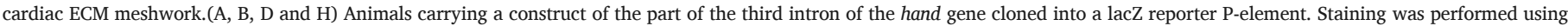

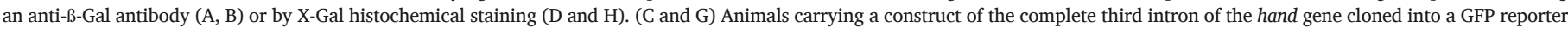

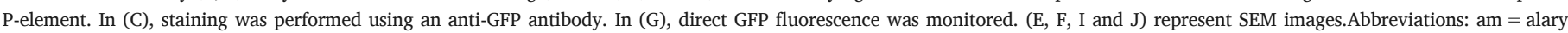

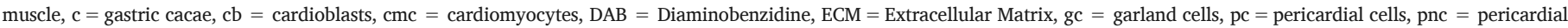
nephrocyte, $\mathrm{pv}=$ proventriculus, $\mathrm{rg}=$ ring gland, $\mathrm{sm}=$ somatic muscle, $w \mathrm{w}=$ wing heart. 
cells remain small, display attenuated expression of marker genes (e.g. handC-GFP) and show deformed nuclei, which presumably indicates on-going cell death (Sellin et al., 2006). The persisting pericardial cells are wrapped into the cardiac ECM fibre network that connects the heart tube and the alary muscles. This particular architecture is maintained into adulthood (Fig. 1). Larval pericardial cells (Fig. 1C, E, F and Fig. 4A-E) are found preferentially in close association with the posterior heart chamber, where the three pairs of functional ostia are situated (Chen et al., 2016; Curtis et al., 1999; Molina and Cripps, 2001). Therefore, haemolymph flows around the pericardial cells before entering the heart tube, which may support the efficient filtering and removal of unwanted products from the haemolymph by the pericardial cells.

\subsection{Ultrastructure, labyrinth channel compartment and slit diaphragms}

Ultrastructural analyses of garland and pericardial nephrocytes in various insects have provided robust evidence of high endocytic activity in larval and adult nephrocytes involved in the uptake of unwanted products from the haemolymph (Bowers, 1964; Brockhouse et al., 1999; Crossley, 1972; Crossley, 1985; Lehmacher et al., 2012; Mills and King, 1965; Sanger and McCann, 1968). The basement membrane covering garland or pericardial nephrocytes serves as a barrier and filtration system for haemolymph content before it reaches the cell membrane for endocytosis (Fig. 4A \& D). The most pronounced ultrastructural feature of insect nephrocytes is the presence of a labyrinthine channel system formed from extensive membrane invaginations (Fig. 4A \& B). These invaginations separate the cell membrane from the basement membrane and collectively form a large channel compartment where endocytosis occurs. At each invagination, a junctional complex, first described as a desmosome, links the plasma membrane (Brockhouse et al., 1999; Crossley, 1972). This linker structure, now known as a slit diaphragm, acts as a second barrier that size-restricts the passage of large molecules into the channel system (Fig. 4B). Uptake assays with probes of different molecular mass showed that molecules up to $70 \mathrm{kDa}$ could pass the slit diaphragm filtration barrier of GCNs and PCNs (Hermle et al., 2017; Zhang et al., 2013a). Therefore, the cut-off size in insect nephrocytes is similar to glomerular filtration in mammals (Hamano et al., 2002).

This nephrocyte filtration barrier shares many similarities with the vertebrate slit diaphragm established by podocytes in the nephrons of the kidney (Weavers et al., 2009; Zhuang et al., 2009). Podocytes display foot processes (pedicels) that extend to capillaries of the glomerulus. A filtration barrier is formed between the pedicels, the so-called slit diaphragm (Wartiovaara et al., 2004). Similarities between the insect and vertebrate filtration slit apparatuses are seen at the ultrastructural, functional and molecular levels. Neph1 and Nephrin are major constituents of the vertebrate podocyte slit diaphragm. Mutations in neph1 or nephrin lead to nephrotic syndrome, which is caused by detachment of podocytes from the basement membrane and a malformed or missing slit diaphragm (Donoviel et al., 2001; Putaala et al., 2001). Drosophila harbours two Neph1 orthologues: Dumbfounded (Duf) (also known as Kin of irre (Kirre)) and Roughest (Rst). In addition, there are two Nephrin orthologues: Sticks and Stones (Sns) and Hibris (Hbs). Sticks and Stones (Sns) and Dumbfounded (Duf/Kirre) are expressed throughout the insect's lifetime in both nephrocyte types (garland and pericardial cells), and Duf and Sns proteins colocalise at the nephrocyte slit diaphragm in garland nephrocytes (Weavers et al., 2009; Zhuang et al., 2009). Mutations in duf or sns cause a wide spectrum of developmental defects due to the broad function of the proteins in several important biological processes (e.g. during myoblast fusion) (Abmayr and Pavlath, 2012). Most notably, mutant flies develop nephrocytes lacking the slit diaphragm and labyrinth channel compartment (Weavers et al., 2009; Zhuang et al., 2009), which are therefore non-functional.

\subsection{Aim of this work}

Nephrocyte ageing has not been analysed in detail. This work focuses on the ultrastructural analysis of PCNs in D. melanogaster at different develop- mental stages. We complete and extend previous ultrastructural studies on pericardial nephrocytes, which mainly concentrated on cells at late larval stages (Brockhouse et al., 1999; Crossley, 1972; Crossley, 1985; Fife et al., 1987; Tepass and Hartenstein, 1994) or on pericardial cells of adult insects from various taxa (Bowers, 1964; Chagas and Caetano, 2003; Crossley, 1972; Mills and King, 1965; Nogueira et al., 1995; Poiani and da Cruz-Landim, 2007; Sanger and McCann, 1968). Less attention has been paid to the ultrastructure of embryonic PCNs. We asked if none, one, two or all three of the molecularly distinguishable PCNs differentiate a labyrinth channel compartment and slit diaphragm during late embryogenesis or whether the odd-skipped expressing subpopulation (the only one that is assumed to survive into adulthood (Das et al., 2008a,c) develops ultrafiltration structures only later during larval development. Furthermore, we present ultrastructural investigations of PCNs at larval and adult stages, including an in-depth analysis of PCN ultrastructure degeneration upon ageing. This study is intended to serve as a reference for future functional studies on nephrocyte function. When using nephrocytes as a model for genetic screening purposes or to investigate the specific role of genes involved in endocytosis, histological changes occurring upon ageing need to be taken into account when interpreting structural data.

\section{Materials and methods}

\subsection{Drosophila stocks}

Fly strains used in this study were white ${ }^{1118}$, handC-GFP and handC-lacZ (Sellin et al., 2006).

\subsection{Immunohistochemistry}

Wandering third instar larvae were dissected and stained as previously described (Drechsler et al., 2013). The following antibodies were used: rabbit anti-Duf (1.1000), rabbit anti-Amn (1:100) and rabbit anti-GFP (1:2000, Abcam). Secondary antibodies were anti-mouse Cy2/Cy5 and anti-rabbit Cy3/Cy5 (1:100 Dianova/Abcam). Anti-Amn was described previously (Ivy et al. 2015). Anti-Duf was raised in rabbit against a synthetic polypeptide corresponding to amino acids 32-46 of Kirre/Duf (KSKKNKSSQSSHHGD) and will be described in detail elsewhere.

\subsection{Transmission electron microscopy}

Embryos (white ${ }^{1118}$ ) were fixed in $2 \%$ glutaraldehyde (Sigma, Germany) and $1 \%$ osmium tetroxide in cacodylate buffer (pH 7.4, Sciences Service, Germany) for $2 \mathrm{~h}$ at $4{ }^{\circ} \mathrm{C}$. Post-fixation was performed in $1 \%$ osmium tetroxide for $1 \mathrm{~h}$ at $4^{\circ} \mathrm{C}$. Subsequently, embryos were dehydrated in a graded ethanol series and permeabilized in three successive steps by applying $100 \%$ acetone $(2 \times 5 \mathrm{~min})$, a mixture of $100 \%$ acetone and Epon 812 (1:1) overnight at room temperature (RT), Epon 812 for $4 \mathrm{~h}$ then overnight, each time at RT. Finally, embryos were embedded in Epon 812 (Fluka, Buchs, Switzerland) and polymerised for $48 \mathrm{~h}$ at $60^{\circ} \mathrm{C}$. Larvae were processed as described in Lehmacher et al. (2012) with minor modifications. Briefly, abdomen of larvae were prepared and fixed for $4 \mathrm{~h}$ at RT in $2 \%$ glutaraldehyde (Sigma, Germany)/4\% paraformaldehyde (Merck, Germany) in artificial haemolymph, subsequently washed in $0.5 \mathrm{M}$ cacodylate buffer $\mathrm{pH} 7.4$, post-fixed for $2 \mathrm{~h}$ at RT in $1 \%$ osmium tetroxide in $0.5 \mathrm{M}$ cacodylate buffer $\mathrm{pH} 7.4$ (sciences services, Germany), dehydrated stepwise in a graded ethanol series and embedded in Epon 812. Pupae were taped down and the puparium removed. The cuticle of the insect was perforated with a needle. Adults were first anaesthetised with carbon dioxide; then the ventral body side and head were removed with a razor blade. Fixation was performed in a mixture of $1 \%$ glutaraldehyde and $4 \%$ formaldehyde in $0.5 \mathrm{M}$ cacodylate buffer $\mathrm{pH} 7.4$ (sciences services, Germany) overnight at $4{ }^{\circ} \mathrm{C}$. Specimens were then post-fixed in $1 \%$ osmium tetroxide in $0.5 \mathrm{M}$ cacodylate buffer $\mathrm{pH} 7.4$ (sciences services, Germany) for $1-5 \mathrm{~h}$ at RT, dehydrated in a graded ethanol series and permeabilized in three successive steps by 
applying $100 \%$ acetone $(2 \times 5 \mathrm{~min})$, a mixture of $100 \%$ acetone and Epon 812 (1:1) overnight at RT, Epon 812 for $4 \mathrm{~h}$ and afterwards overnight, each time at RT. Finally, embryos were embedded in Epon 812 and polymerised for $48 \mathrm{~h}$ at $60^{\circ} \mathrm{C}$. Ultrathin sections $(70 \mathrm{~nm})$, were on an ultramicrotome (UC6 and UC7 Leica, Wetzlar, Germany), mounted on copper slot grids. Sections were stained for $30 \mathrm{~min}$ in $2 \%$ uranyl acetate (sciences services, Germany) and $20 \mathrm{~min}$ in $3 \%$ lead citrate (Roth, Germany). TEM images were acquired with a Zeiss 902 on a Zeiss $120 \mathrm{kV}$ transmission electron microscope.

\subsection{Scanning electron microscopy (SEM)}

Preparation of Drosophila tissue for SEM has been previously described (Hüsken et al., 2015). After preparation, tissue was incubated in $100 \%$ ethanol then critical point dried (Balzer Union CPD010, Wiesbaden, Germany). Subsequently, tissue was glued onto aluminium studs, covered with a platinium coat using a Polaron E5000 Sputter Coater, and examined on a Zeiss Auriga SEM.

\section{Results and discussion}

\subsection{PCNs at late embryogenesis}

The population of 110-130 pericardial cells fall into different classes distinguishable by their position relative to the heart tube and by the expression of specific marker genes (Fig. 2A \& B): dorsally located pericardial cells co-expressing even-skipped and tinman (EPCs, two per abdominal hemisegment, Fig. 2C), ventrally located pericardial cells expressing tinman (TPCs, four per abdominal hemisegment, Fig. 2D \& E) and laterally located cells expressing odd-skipped (OPCs, four per abdominal hemisegment, Fig. 3A-C) and (Ward and Skeath, 2000). To date, functional differences have not been described for the different subsets of embryonic pericardial cells with a few exceptions, eight of the even-skipped/tinman-expressing dorsally located embryonic pericardial cells lose Tinman expression and differentiate into so-called wing hearts, organs that are crucial for proper development of the wings (Lehmacher et al.,
2009; Tögel et al., 2008, 2013). Very recently it has been shown that the most anterior EPCs form a novel cardiac outflow component, the outflow hanging structure (Zmojdzian et al., 2018).

We extend our previous ultrastructural studies on heart development (Lehmacher et al., 2012) and analyse the developing labyrinth channel system and slit diaphragm in nephrocytes (Figs. $2 \& 3$ ). Accordingly, we conducted an in-depth investigation of the ultrastructure and histology of three subpopulations of pericardial cells present in the late embryo. We utilised the same embedded embryos for subsequent analysis of the garland nephrocytes situated in the proventriculus tissue for comparison. These embryonic garland cells are known to develop an extensive ramified labyrinth channel system formed by membrane invaginations and slit diaphragm at the entry of membrane invaginations (Weavers et al., 2009). Therefore, we gathered ultrastructural data available for PCNs and GCNs from the same animals at a specific developmental stage. Images captured for the embryonic garland cells are shown in Fig. 3D-E.

\subsubsection{Dorsolateral pericardial cells (Even-skipped/Tinman expressing)}

The two Even-skipped-expressing pericardial cells (EPCs) present in a hemisegment arise from the $\mathrm{P} 2$ progenitor present in the cardiogenic mesoderm (Carmena et al., 1998; Han and Bodmer, 2003). All EPCs express Pericardin, a structural cardiac ECM protein (Tögel et al., 2008), Even-skipped and Tinman (Azpiazu et al., 1996). At the ultrastructural level, EPCs at stage 16/17 show a large ramified rough endoplasmic reticulum (rER) network and occasionally coated vesicles from the endocytic pathway are visible. However, the characteristic histological features of mature nephrocytes, fully differentiated slit diaphragms and an extensive labyrinth channel system, are not seen in embryonic EPCs (Fig. 2C).

\subsubsection{Ventral pericardial cells (Tinman expressing)}

A specific function for the ventral pericardial cells (TPCs) has, to our knowledge, yet to be identified. Four cells per hemisegment arise throughout symmetric cell division (Ward and Skeath, 2000). These cells express Pericardin (own data); therefore, they contribute to the synthesis and secretion of Pericardin and perhaps other matrix proteins. At the ultrastructural level, we

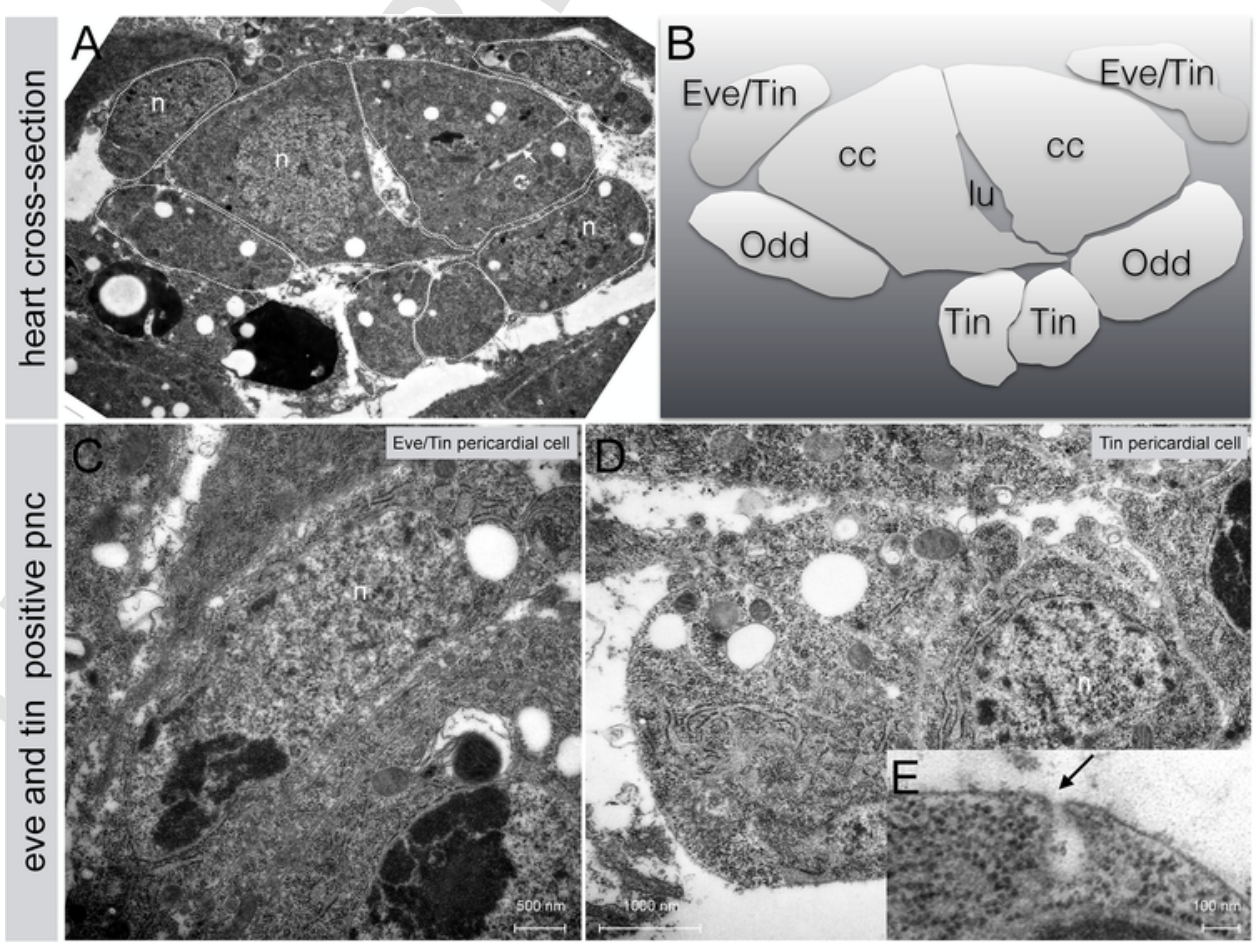

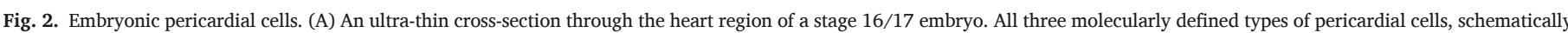

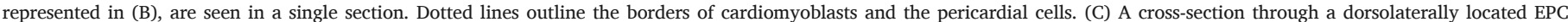

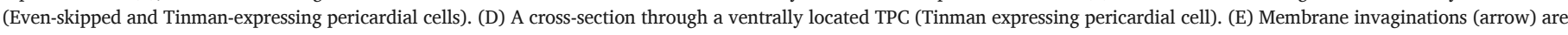
seen very rarely in TPCs. All pictures shown are TEM images.Abbreviations: $c c=$ cardiomyocyte, $\mathrm{lu}=$ lumen, $\mathrm{n}=$ nucleus. 


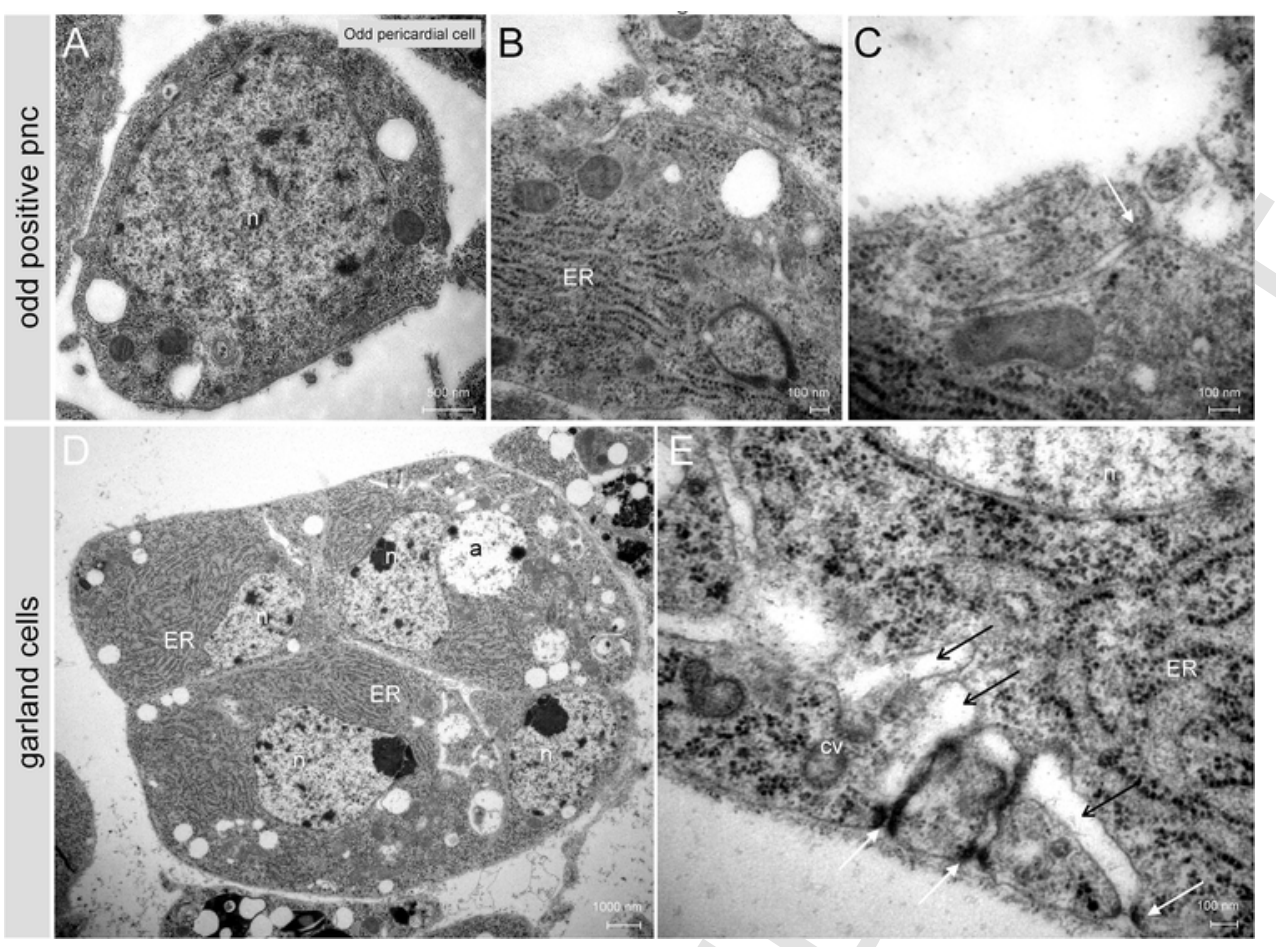

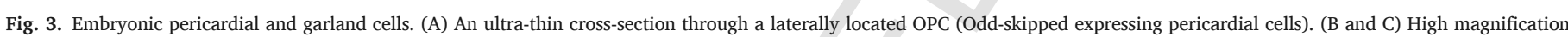

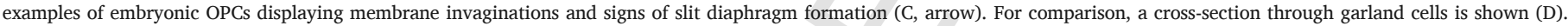

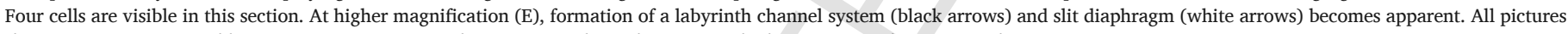
shown are TEM images.Abbreviations:? ? = ? ? -vacuole, $\mathrm{cv}=$ coated vesicle, $\mathrm{ER}=$ endoplasmatic reticulum, $\mathrm{n}=$ nucleus.

see a large network of rER (rough endoplasmatic reticulum), several vacuoles and, rarely, membrane invaginations. Although speculative, this might be taken as an indication for pino- or phagocytic activity (Fig. 2E).

\subsubsection{Ventrolateral pericardial cells (odd-skipped expressing)}

The four Odd-skipped-expressing cells (OPCs) in a hemisegment originate from different cell lineages. The anterior two OPCs arise from an asymmetric cell division, each sharing a progenitor with two corresponding cardiomyoblasts. The posterior OPCs arise from a symmetric cell division (Han and Bodmer, 2003; Popichenko and Paululat, 2004; Ward and Skeath, 2000). All OPCs express Pericardin and thereby these cells contribute to matrix protein production. We see very rarely that late embryonic OPCs differentiate structures that might be either endocytic events or the begin of labyrinth channel differentiation (Fig. 3B-C) that, once slit diaphragms are formed, serve as filtration barriers.

\subsubsection{Garland cells}

The 15-20 garland cells in Drosophila melanogaster are clustered and encircle the proventriculus in a necklace-like arrangement (Figs. 1B \& D, 3D-F). Garland cells originate with a single nucleus but eventually fuse to form bi-nucleated mature garland cells (Zhuang et al., 2009). They display all the characteristic structural details representative of nephrocytes as shown previously (Weavers et al., 2009). For comparison with pericardial nephrocytes at the same developmental stage, we analysed the ultrastructure of the garland cells from same animals. Compared to the embryonic pericardial cells, the embryonic garland cells display a differentiated labyrinth channel system connected with the body cavity via membrane invaginations. Accumulation of electron-dense material at the entry of the invaginations indicates the formation of the slit diaphragm (Fig. 3F). We also observe a ramified network of rER, coated vesicles and early and late endosome. We hypothesised that the garland cells in the late embryo are already designated as nephrocytes and may already be functional and highly endocytic.

\subsection{PCNs in third instar larvae and pupae}

At late stage embryogenesis, about 110-130 Pericardin-positive pericardial cells belonging to the three subpopulations described above, are visible (Alvarez et al., 2003; Sellin et al., 2006). The majority of the cells disappear, and 40-50 pericardial cells from the Odd-skipped-expressing cluster remain in the third instar larvae (Das et al., 2008c; Kimbrell et al., 2002; Mandal et al., 2004; Rizki, 1978; Sellin et al., 2006). These cells differentiate into the pericardial nephrocytes (PCNs) with a large centrally located nucleus and zonal distribution of endocytic vesicles at different stages of the endocytic pathway (Fig. 4A-E). Third instar larvae PCNs are covered by a thin layer of ECM (see Fig. 4C). We have previously shown that PCNs in third instar larvae are connected to the heart tube and to the alary muscle through a ramified meshwork of ECM fibres (Lehmacher et al., 2012). The PCN cell membrane shows invaginations that form the large interconnected labyrinth channel system (Fig. 4B). This has been suggested by several authors to be the site of endocytosis (Mills and King, 1965). Even 50 years earlier, with no ultrastructural data, the phagocytic activity of insect pericardial cells was documented (Hollande, 1916). In agreement with these classical results, we found coated vesicles in statu nascendi, where budding occurs at the invaginations of the cell membrane at the tips of the labyrinth system (Fig. 4D). Early endosome fusion and formation of alpha- and beta-vacuoles appear. Typical multi-vesicular bodies are not found at this developmental stage, but endocytosed vesicles are visible occasionally.

Membrane invaginations, the entry into the labyrinth channel system, are characterised by the membrane-membrane interconnecting slit diaphragm. Slit diaphragms are formed between cells in the vertebrate podocytes and by the membrane invagination of single PCNs in Drosophila, in both cases by the same highly conserved proteins (Helmstädter and Simons, 2017). Interestingly, we also found the slit diaphragm inside the labyrinth channel system (Fig. 4B), within the same channel. Although speculative at the moment, this might be due to the development of the labyrinth channel system. Potentially, existing slit diaphragms could be internalised upon further development of

the

labyrinth 


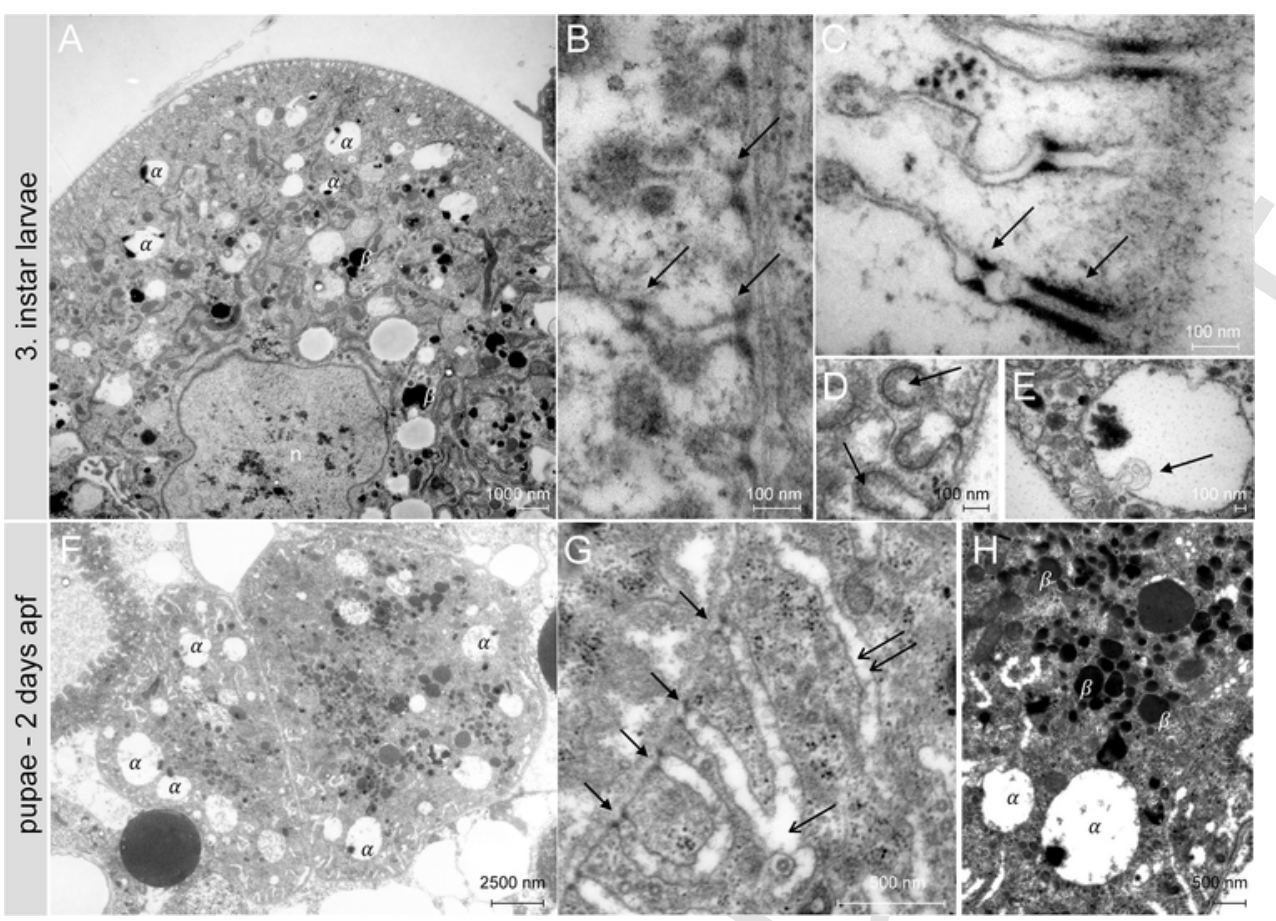

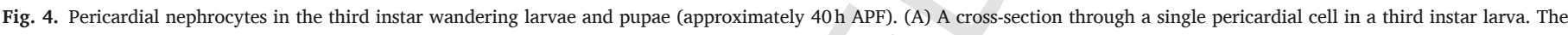

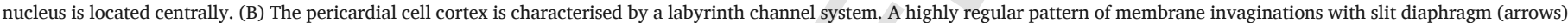

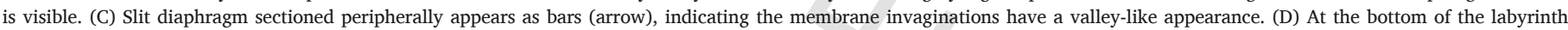

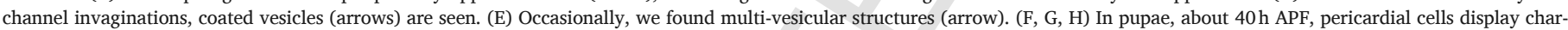

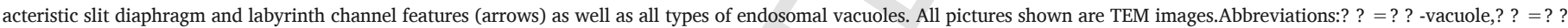
-vacuole, $\mathrm{n}=$ nucleus.

channels. The occurrence of multiple consecutive slit diaphragms can also be induced experimentally in garland nephrocytes, e.g. by RNAi-mediated down-regulation of Coq2, which is the Drosophila 4-hydroxybenzoate polyprenyltransferase involved in coenzyme $\mathrm{Q}$ biosynthesis (Hermle et al., 2017). An alternative explanation is supported by previous observations from Crossley (1985). Tangential sections of Calliphora erythrocephala adult nephrocytes showed a fingerprint-like pattern of slit diaphragms with a zipper-like appearance. Similarly, a fingerprint-like pattern of the slit filtration apparatus has been demonstrated for garland nephrocytes using SNS and Duf immunohistological staining (Hermle et al., 2017). We cannot rule out that the consecutive appearance of slit diaphragms reflects multiple sections of the same longitudinal (fingerprint)-structure (Fig. 4C). We were also able to identify pericardial nephrocytes in developing pupae at about 35-40h after puparium formation (APF). PCNs display all of the characteristics of active nephrocytes, with alpha-, and beta-vacuoles (Fig. 4F), slit diaphragms and a ramified labyrinth channel system (Fig. 4G \& H). The appearance of characteristic vesicles at different stages of the endocytic pathway indicates that the pericardial nephrocytes are active scavenger cells in the pupae.

\subsection{Ageing-associated morphological changes of nephrocytes in adult flies}

Garland and pericardial nephrocytes have become popular model systems to investigate the endocytic pathway components and slit diaphragm differentiation. As scavenger cells, they process and store waste products. We speculate that these cells undergo individual ageing dependent on the type and amount of material they have internalised, stored or processed. To address this question, we asked what the individual histological differences are that potentially occur in the adult pericardial nephrocytes upon ageing of the fly. Therefore, we investigated the ultrastructure of PCNs from one and six-week-old adult females and males.

In young flies, the nephrocyte cytoplasm is typically composed of two distinct regions: the peripheral or cortical region and a central perinuclear region (Koenig and Ikeda, 1990) (Fig. 5). The cortical compartment by invaginations of the plasma membrane. Slit diaphragms are located at the openings of the tubules. The cortical compartment is the main endosomal region and contains numerous variably-sized vacuoles and branching interconnected tubules (Koenig and Ikeda, 1990). The region contains a zone with early endosomes and clathrin-coated vesicles formed under the invaginated lacunas. The early endosomal belt is followed by the late endosomal layer, which contains large electron-lucent vesicles with one or more electron-dense cores (so-called alpha-vacuoles) (Lôrincz et al., 2016) sometimes observed to be connected to the tubular system (Koenig and Ikeda, 1990; Kosaka and Ikeda, 1983). The cortical region is followed by the central perinuclear region, which is enriched with dark beta-lysosomes, abundant rER arranged as tubular cisternae, which can fill large sections of the PCNs, and Golgi (Koenig and Ikeda, 1990). This characteristic nephrocyte-specific zonation is clearly mirrored in our ultrastructural analyses of the third instar larvae and one-week-old adult female and male Drosophila PCNs (Figs. 4A, see 5A1 \& A2, 7A \& B), but begins at the pupal stage.

In contrast, inspection of TEM sections revealed that the subcortical zonal regions of female and male PCNs seems to be clearly reduced as well as the zones of? ?- and? ?-vacuoles but they are still distinguishable (Fisg. 5C1-3, 6M \& N and 7D \& E). Interestingly, our ultrastructural study furthermore revealed that significant morphological PCN differences are detectable in peer individuals and even within the same individual. These differences are prominent in two-week-old adult Drosophila (Fig. 5B1-3). Therefore, we exemplarily illustrated three overview TEM images of different PCNs per age (Fig. 5). In one-week-old adult female PCNs, nephrocyte-zonation shows almost no variability in terms of its characteristic arrangement of endocytic vesicular stages and organelles. The early endosomal belt is located in the most peripheral area of the PCN followed by the region of the late endosomal layer enriched with its characteristic alpha-vacuoles (Fig. 5A1-3). Its' perinuclear region varied in terms of abundance of flattened rER and the amount of characteristic dark beta-vacuoles, which is mainly dependent on the illustrated PCN region and its metabolic state. However, in one-week-old male PCNs, we observed a narrower cortical zone and an accumulation of large beta-vacuoles (up to $3 \mu \mathrm{m}$ in diame- 


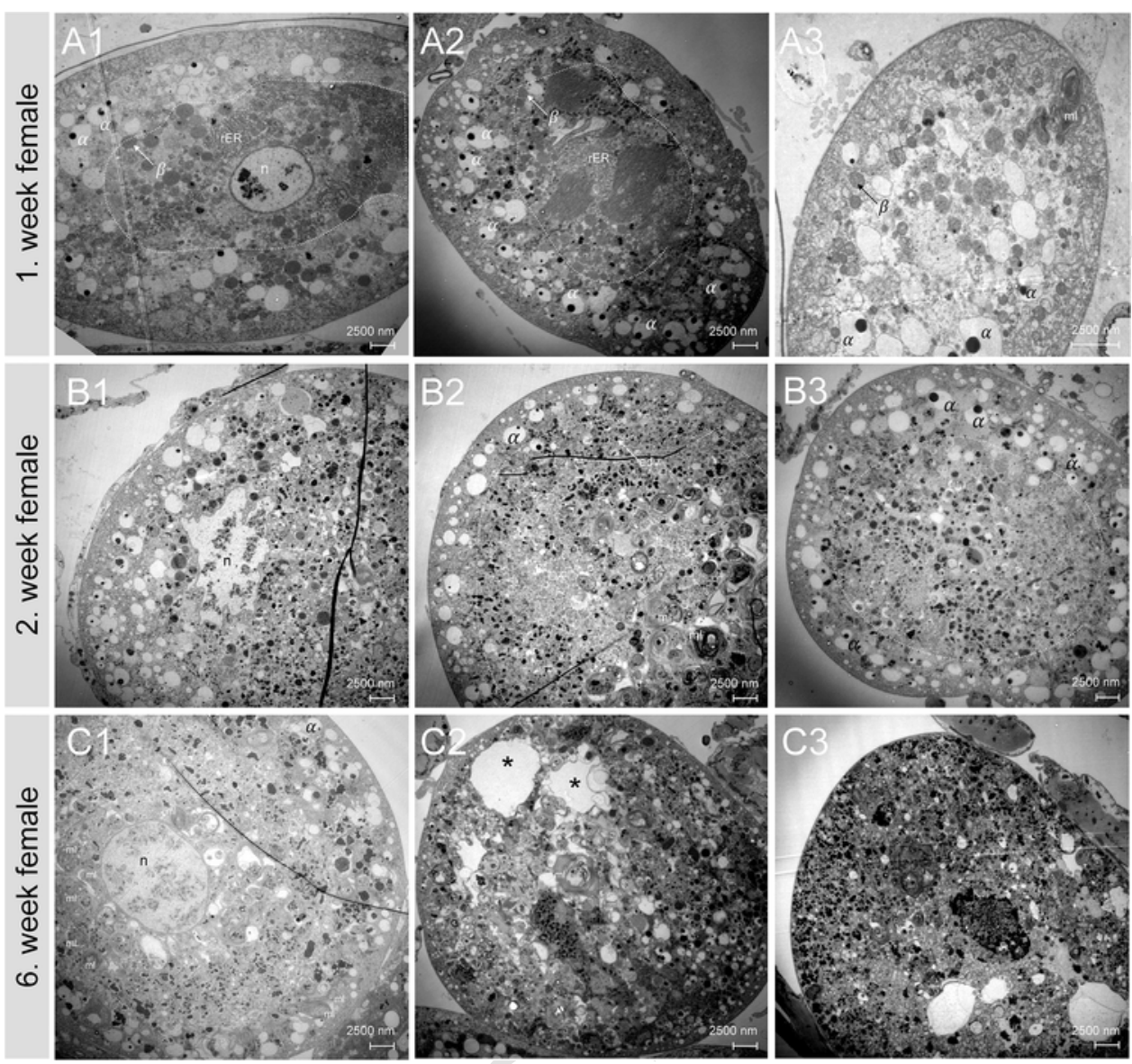

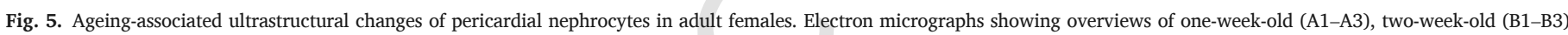

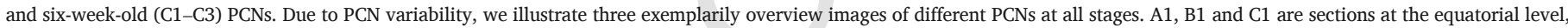

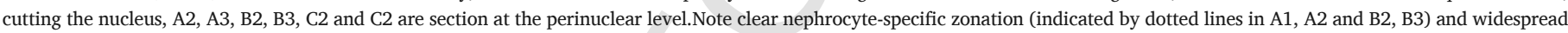

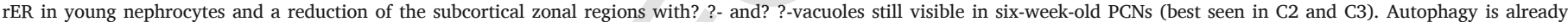

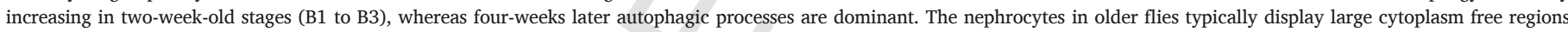

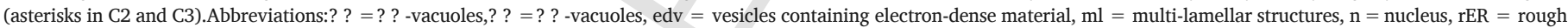
endoplasmaic reticulum.

ter) containing electron-dense cores of irregular size and location (best seen in Fig. 7B, C \& C''). The presence of multi-lamellar structures and single-membrane vesicles with electron-dense material indicates late autophagic vacuoles such as autophagolysosomes and amphisomes (Nixon, 2007). This morphological difference between young female and male PCNs could be an indication of gender-based differences in the ageing process. To substantiate this observation, a more detailed analysis will be necessary.

Most striking is the observation that only one week later, in two-week-old female adult PCNs, enormous morphological variability in sequence, composition and expansion of nephrocyte-zonation became visible (best seen in Fig. 5B2 \& B3). The occurrence of almost all stages of the autophagic pathway is, to some extent, already present in the central perinuclear region at two-weeks old PCNs (Fig. 6L). This region includes pre-autophagic structures, double-membrane-limited autophagosomes, autophagosomes containing multiple smaller compartments, autophagolysosomes with electron-dense intraluminal material, multi-lamellar structures, late autophagic vacuoles and lysosomes. Of particular note is the abundance of smaller dark, electron dense, irregular inclusions following the late endosomal belt (Fig. 5B1-3). Regions of abundant rER of one-week-old adult Drosophila as shown in Fig. 5A1 \& A2 are not detectable. The cortical zone is in part diverse (Fig. 6F-H) but as demonstrated in Figs. 5B1-3 and 6F, the main components of the cortical region of the two-week-old adult Drosophila show ultrastructural composition comparable to the one-week-old stage. In most cases main portions of the labyrinthine channel system and the slit diaphragms are intact, which is comparable to younger PCN stages (Fig. 6I). However, in a large proportion of the pericardial cells, the highly organised nephrocytic cortical zone is significantly disrupted at this age (Fig. 6G \& H). In some areas, the zonation between the early and late endosomal belt is completely absent, and only a few smaller-sized alpha-vacuoles are visible (Fig. 6G). Furthermore, the labyrinthine system and the early endosomal vesicles are not formed properly (Fig. $6 \mathrm{H}-\mathrm{L}$ ). This morphological change is accompanied by a disarrangement of the junctional complex of the slit diaphragms (Fig. $6 \mathrm{~J}$ ) or their complete loss (Fig. 6K).

In PCNs of six-week-old adult female Drosophila, autophagy is the dominant process which is evident by the many autophagic vacuoles, including large immature autophagosomes surrounded by double-membranes containing small vesicles and vacuoles (Fig. 6N), numerous multi-lamellar structures (Fig. 6Q) and late autophagic vacuoles such as autophagolysosomes and amphisomes. In particular, we found huge electron-lucent areas (Fig. 5C2 \& C3), which in some cases fill more than half of the PCN. In many PCNs, we found autophagic vacuoles are situated against the outermost cell membrane. The nephrocyte-specific cortical region with its characteristic labyrinth channel system is not detectable (Figs. 5C \& 6M) and slit diaphragms are disturbed or absent in these PCNs (Fig. 60 \& Q). PCNs showing the characteristic cortical region with normal slit diaphragms and lacunae very often form tubules with U-shaped loops that do not continue toward the perinuclear region (Fig. $6 \mathrm{~N} \& \mathrm{~N}^{\prime}$ ). A decrease or absence of alpha-vacuoles is seen. The so-called 'transitional zone', which separates the cortical and perinuclear region, and contains numerous mitochondria, vacuoles and Golgi centres, is missing in these old adult PCNs. Instead, in many cases, increased autophagic vacuoles are detectable (Fig. 6N). 

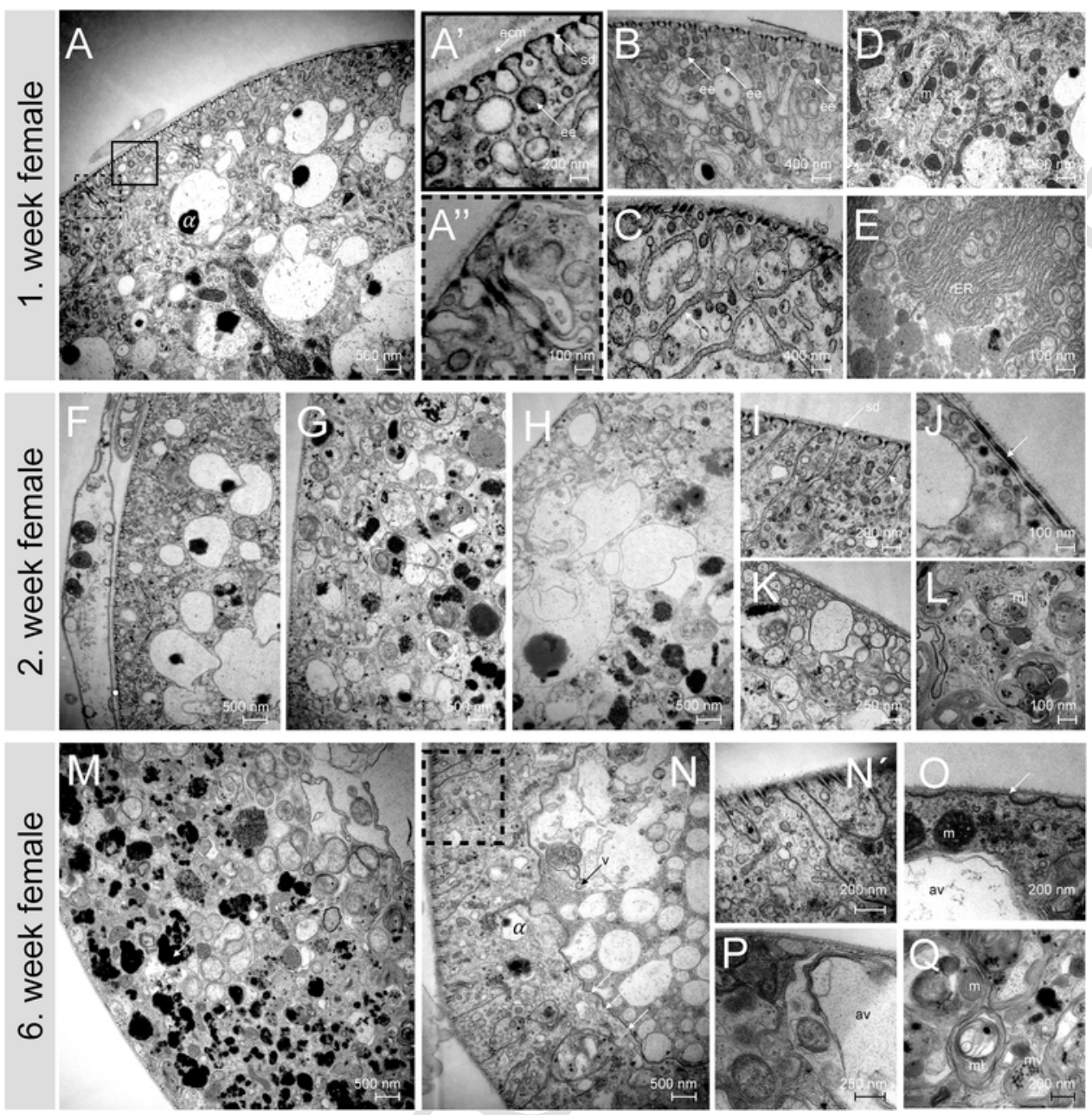

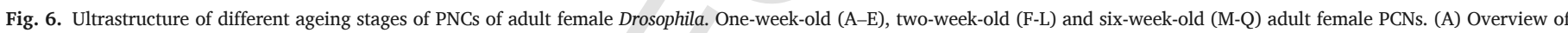

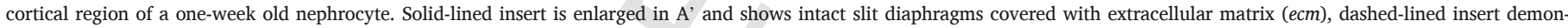

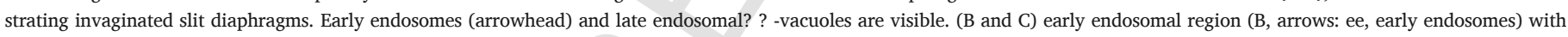

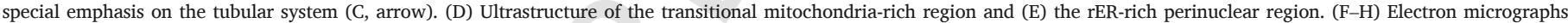

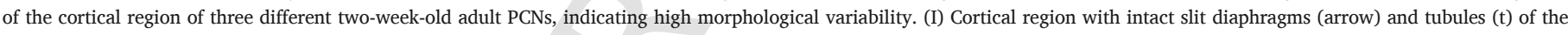

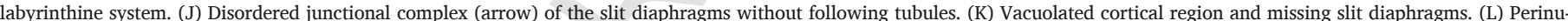

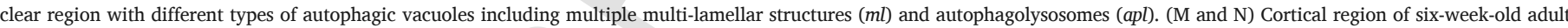

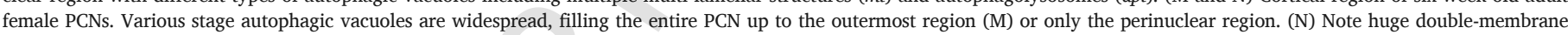

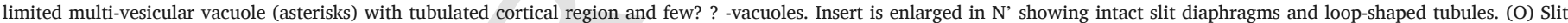

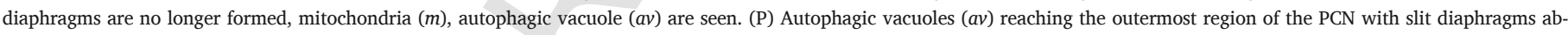

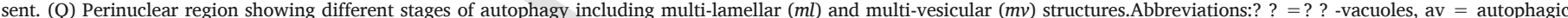

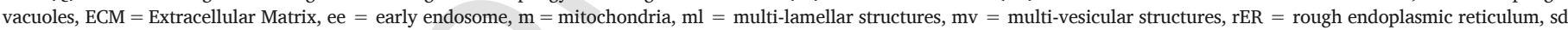
$=$ slit diaphragm, $\mathrm{t}=$ tubules; $\mathrm{v}=$ vesicles.

In male six-week-old specimens, we found a significant increase in electron-dense inclusions filling almost the entire PCN (Fig. 7D-F). The presence of multi-lamellar structures and single-membrane vesicles containing smaller compartments or dark material indicates that late autophagic vacuoles are abundant. In some areas, we could not find any slit diaphragms (Fig. 7G). Nevertheless, we could observe a cortical zone with abundant early endosomes and alpha-vacuoles and intact slit diaphragms (Fig. 7F \& F'). Autophagic activity is increased by some conditions such as oxidative stress, nutrient limitations or growth factor withdrawal (Nagy et al., 2015). The extent, to which these conditions are responsible for the increase in autophagy, loss of intact zoning and the presence of intact slit diaphragms in aged PCNs, particularly in younger male individuals, must be studied in detail.

Detailed comparative analyses of female and male specimens shows that the one-week-old pericardial nephrocytes harbour an intact slit diaphragm and a cortical labyrinth channel system that appears very regular with a distinct luminal diameter (Figs. $6 \& 7$ ). The ECM covering the PCN displays a homogenous appearance. We see a spacious ER channel system, mainly located near the centre of the cell. Mitochondria are intact, and all stages of endocytic vesicles are visible. In contrast, PCNs of six-week-old females (Fig. 6M-R) and males (Fig. 7D \& E) display a wide range of degenerative processes. This includes the breakdown of the labyrinth channels (which appear bloated or shrunken), absence of membrane invaginations and slit diaphragm. Occasionally we observed malformed, enlarged mitochondria lacking regular cristae structures. Furthermore numerous vesicles are detectable, especially larger ones, containing dark electron-dense material of unknown origin. Often we observed large multi-lamellar bodies, which seem to represent a characteristic feature of older PCNs. Differences between males and females were in the range of individual variations.

We postulate that these variations at the ultrastructural level reflect individual ageing. It seems reasonable to us that each PCN in a single individual animal receives and stores different types of metabolic products and toxic substances and thus appear slightly different in its ultrastructure. Degeneration of nephrocyte histology is also seen when cells are stained for slit diaphragm proteins (Fig. 8). Nephrocytes from younger flies stained with antisera to either 


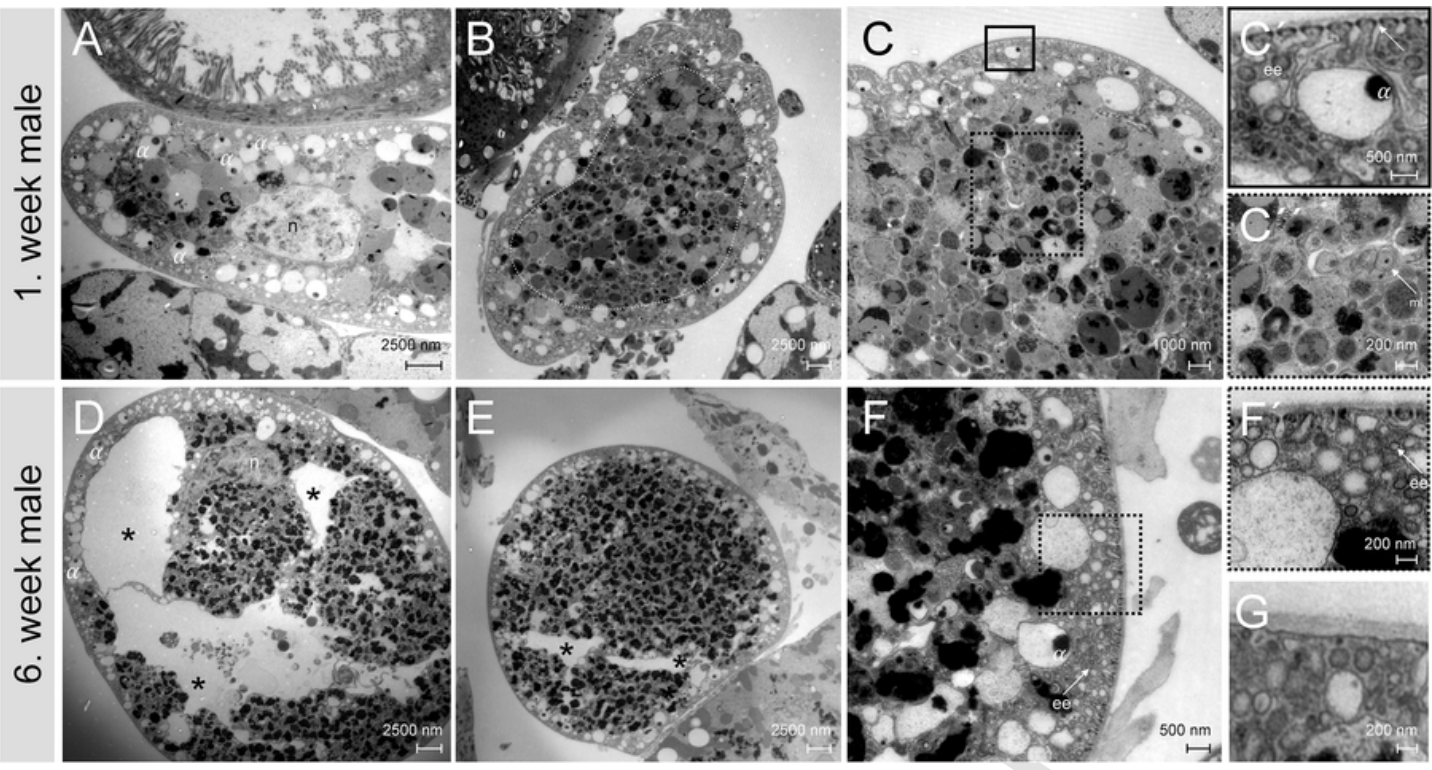

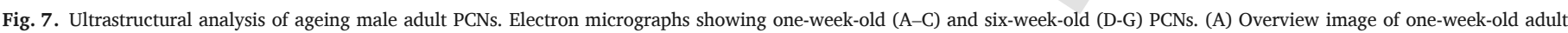

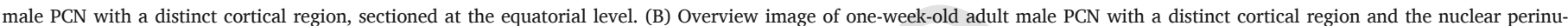

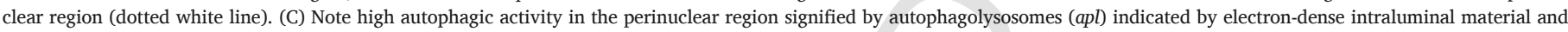

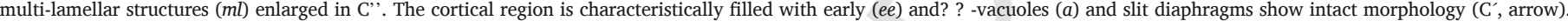

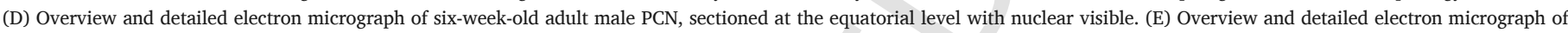

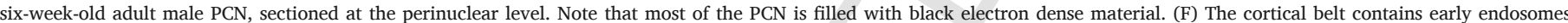

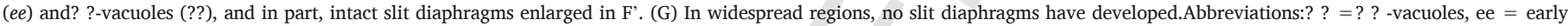
endosome.

Dumbfounded (Duf) or Amnionless (Amn) showed uniform staining, where Duf was expressed at the very edge of the nephroycte surface and Amnionless was sub-surface (Fig. 8). This association reflect the histology of the human glomerulus and upper renal tubules were slit diaphragms give way to proximal renal tubule cells that express very high levels of Amnionless on their apical surface. In older flies (6 weeks old, an age approximating 'late middle age'), the staining for Duf and Amn became far more disrupted, with large areas of the cell surface devoid of Duf staining (Fig. 8A-B), and the cell interior showing signs of accumulated Amn immunoreactivity (Fig. 8C). Detailed analysis of the relationship between Duf and Amn indicated the spatial patterning of the two proteins which is highly regulated in younger nephrocytes and becomes severely disrupted in older cells (Fig. 8D and E), consistent with loss of slit diaphragms seen at the ultrastructural level (Fig. 8F, G).

\section{Conclusion}

Pericardial cells may have different functions at different development stages. During embryogenesis, they lack the characteristic features of nephrocytes, which are the slit diaphragm compartment and a ramified labyrinth channel system. Therefore we postulate that the embryonic pericardial cells have primary functions other than ultrafiltration, e.g. production and secretion of ECM constituents as shown by several authors (e.g. (Drechsler et al., 2013)). However, in the third instar larvae, the pericardial cells have a fully developed labyrinth channel and slit diaphragm, indicating their function as active nephrocytes. Their main function therefore might change during development, being an important source for ECM components during the embryonic stage and later on fulfilling their nephrocytic function. A second function of the embryonic pericardial cells is to provide the source of progenitor cells that later differentiate into larval and adult structure, such as the anterior heart „hanging structure "(Zmojdzian et al., 2018) and the wing heart (Tögel et al., 2008, 2013). This applies for the anteriormost EPCs in the embryo.

The embryonic OPCs differentiate into functional nephrocytes and they are, together with the garland nephrocytes, essential for longevity of the fly. This has been demonstrated by the identification of genes that regulate nephrocyte functionality. One such gene is the Krüppel-like family factor $d K l f 15$ (previously known as Bteb2), which regulates garland and pericardial cell nephrocyte differentiation much like KLF15 in vertebrate podocytes (Fan et al., 2017; Ivy et al., 2015). In dKlf15 mutant embryos, nephrocytes are initially specified by the expression of PCN and GCN markers. Later, during larval development, most nephrocytes die, and adult specimens lack all, or the majority of, scavenger cells. Surviving nephrocytes lack slit diaphragms and the labyrinth channel compartment. Moreover, these cells often display a 'poly-cellular' phenotype, presumably indicating that in the absence of the dKlf15, polytenisation is disrupted and cytokinesis, which is blocked in wild-type nephrocyte differentiation, occurs. The $d K l f 15$ mutant insects survive but are highly sensitive to toxic stress, to which they respond with a shortened lifespan (Ivy et al., 2015). Increased sensitivity to toxic stress has been linked to non- or less-functional nephrocytes (Das et al., 2008b; Ivy et al., 2015; Zhang et al., 2013b). For example, disruption of either nephrocyte differentiation or function does not lead to immediate lethality in flies but causes increased sensitivity to toxic stress associated with a significantly reduced lifespan (Zhang et al., 2013b). Ultrafiltration and endocytic uptake require the activity of several gene products. Recently, a set of 29 genes that share homologies to human genes known to induce monogenic steroid-resistant nephrotic syndrome (SNRS) have been functionally tested in GNCs. Impaired endocytic activity was seen for 16 genes, including genes encoding proteins of the slit diaphragm complex (e.g. Pyd), ECM receptors (e.g. LanB1) and CoQ10 synthesis pathway, which demonstrates the suitability of Drosophila nephrocytes as a model for human disease (Hermle et al., 2017).

Whether pericardial cells execute a direct or indirect measurable influence on heart performance or adult morphogenesis is still under discussion. Heart rate is described as normal in animals that lack functional nephrocytes (Das et al., 2008b; Ivy et al., 2015; Weavers et al., 2009). In contrast, Lim et al. (2014) recently provided evidence for a role for pericardial cells in maintaining normal cardiac function in a paracrine manner. Flies in which ROS levels have been significantly reduced by pericardial cell-specific over-expression of Catalase display deterioration in heartbeat rhythmicity, increased frequency of irregular heartbeats and an increased arrhythmia index (Lim et al., 2014). An additional, but less well-analysed function of pericardial cells is the secretion of extracellular matrix constituents (and maybe other haemolymph proteins). In the em- 

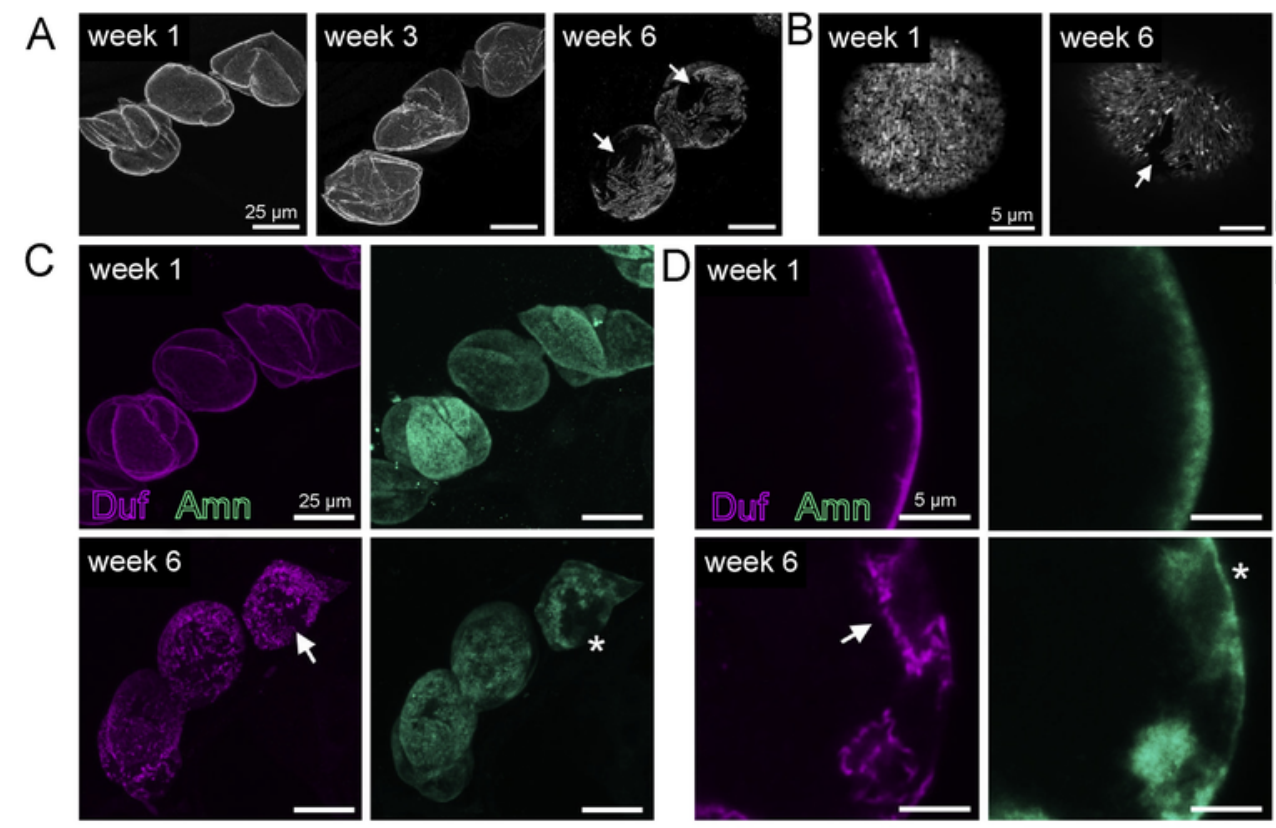

E
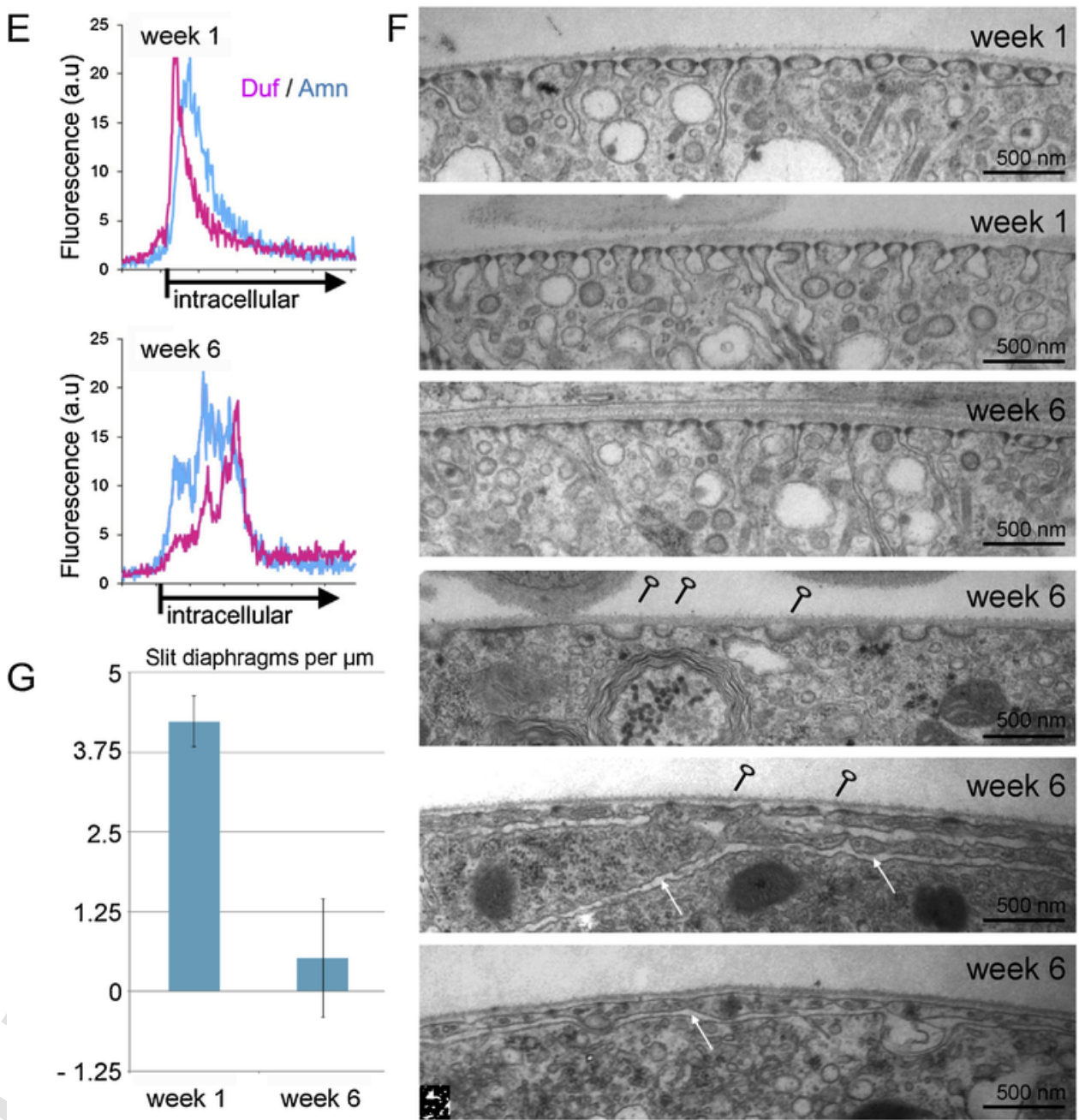

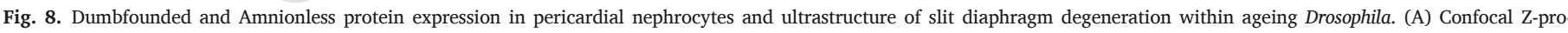

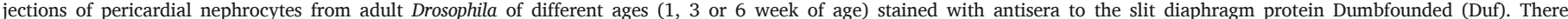

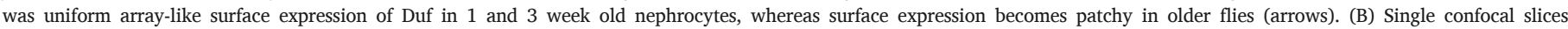

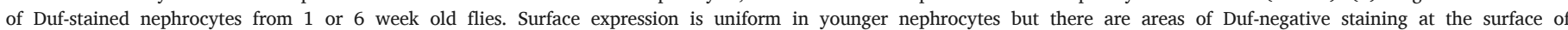

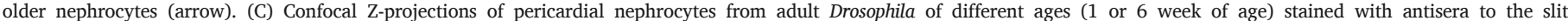

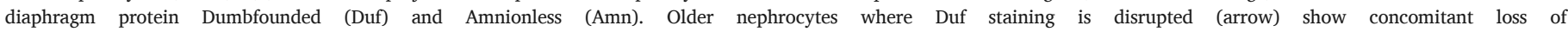




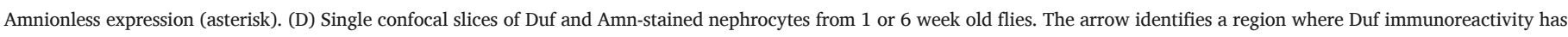

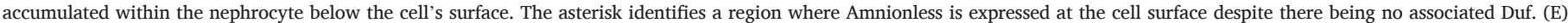

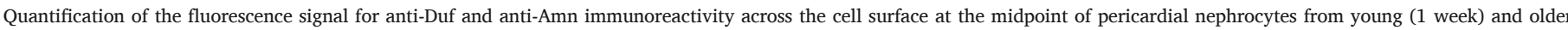

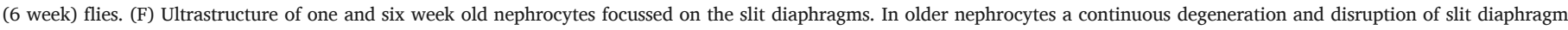

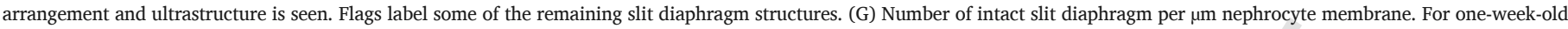

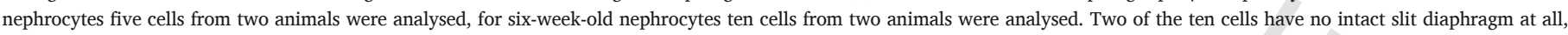
which is the reason for the high variability of the data. All specimens shown were females.

bryo, PCNs are the major resource for Pericardin production and secretion. Pericardin, a collagen IV-like structural ECM protein, is released by pericardial cells and recruited to the cardiac matrix, where it plays an essential role in maintaining cardiac integrity. The absence of Pericardin causes destabilisation of the cardiac matrix and is associated with luminal heart collapse and heart failure (Drechsler et al., 2013; Wilmes et al., in press).

Here we show, for the first time, that PCNs in the adult fly undergo dramatic histological degeneration upon ageing (schematically illustrated in Fig. 9). The slit diaphragms disappear, the labyrinth channel system degenerates and the lysosomal compartment is highly enriched with electron-dense material, which are most likely waste products stored in the old pericardial cells. Upon ageing, nephrocytes were rendered non-functional, they store waste material but they fail to undergo renewal. Thereby we speculate that the ultrastructural changes in the older nephrocytes reflect a continuous degeneration process of PCNs that finally lead to a collapse of the animals' scavenger system. The individuals fail to withstand toxic stress and finally die.

\section{Funding}

This work was supported by grants from the Deutsche Forschungsgemeinschaft to A.P. (DFG PA 13-1, SFB 944 TP7, SFB 944 Z-Project), the DAAD (ProCope program), from the State of Lower-Saxony (ZN2832), as well as the British Heart Foundation to P.H. (FS/13/17/29905).

\section{Acknowledgements}

We acknowledge Kerstin Etzold, Birgit Hemmis and Werner Mangerich for their invaluable assistance with TEM and REM analyses. Furthermore, we thank former students Sara Timm, Kristina Rauf, Anjilie Baller and Meike Frantzheld for their help. We also thank Flybase for generous support over many years. Many thanks to FlyBase for supporting our research community (Drysdale et al., 2008).

\section{Competing interests}

The authors declare no competing or financial interests.

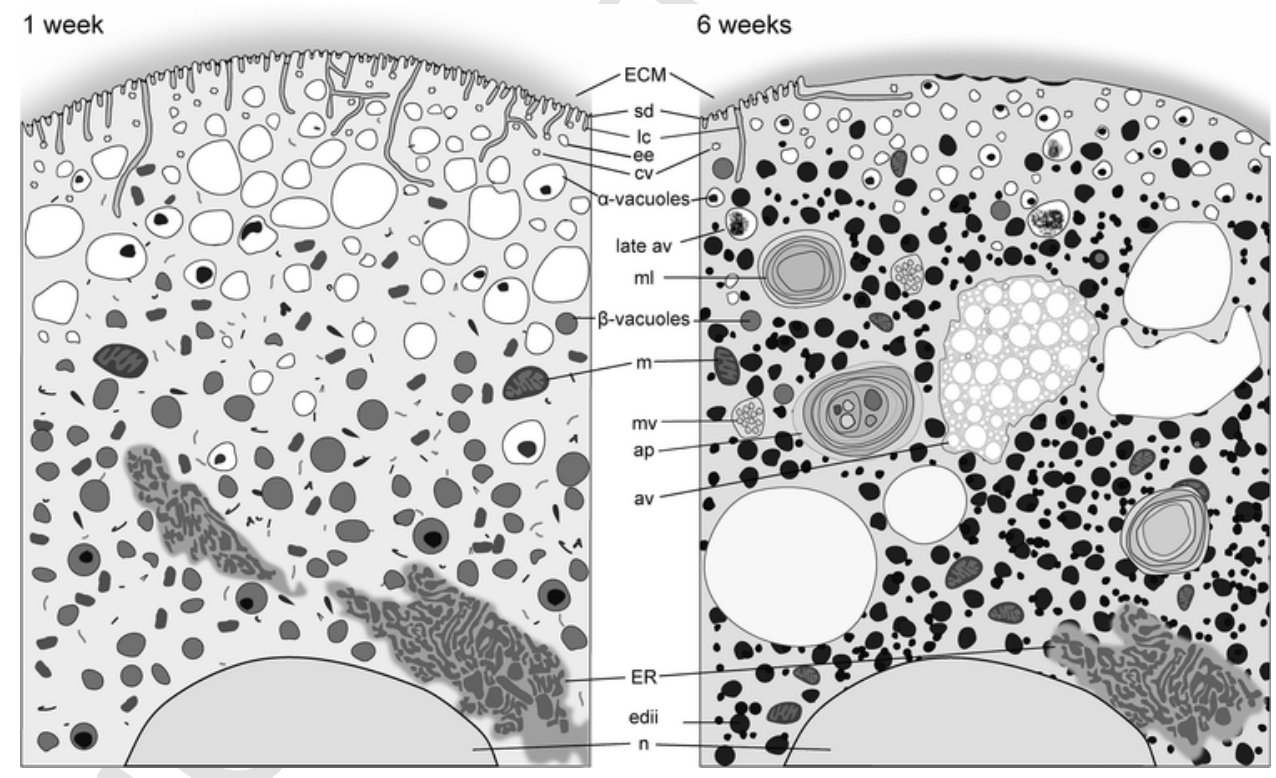

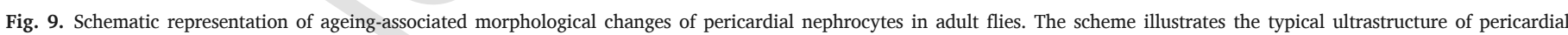

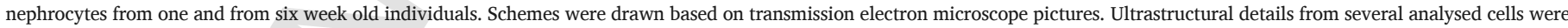

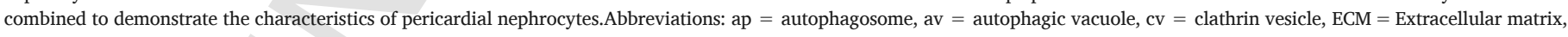

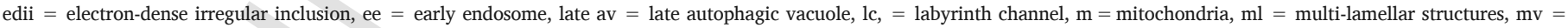
multi-vesicular structures, $\mathrm{sd}=$ slit diaphragm. 


\section{References}

Abmayr, S.M., Pavlath, G.K., 2012. Myoblast fusion: lessons from flies and mice. Development 139, 641-656.

Aggarwal, S.K., King, R.C., 1967. The ultrastructure of the wreath cells of Drosophila melanogaster larvae. Protoplasma 63, 343-352.

Akbar, M.A., Tracy, C., Kahr, W.H., Kramer, H., 2011. The full-of-bacteria gene is required for phagosome maturation during immune defense in Drosophila. J. Cell Biol. 192, 383-390.

Albrecht, S., Wang, S., Holz, A., Bergter, A., Paululat, A., 2006. The ADAM metalloprotease Kuzbanian is crucial for proper heart formation in Drosophila melanogaster. Mech. Dev. 123, 372-387.

Alvarez, A.D., Shi, W., Wilson, B.A., Skeath, J.B., 2003. Pannier and pointedP2 act sequentially to regulate Drosophila heart development. Development 130, 3015-3026.

Azpiazu, N., Lawrence, P.A., Vincent, J.P., Frasch, M., 1996. Segmentation and specification of the Drosophila mesodermGenes Dev. 10, 3183-3194.

Bowers, B., 1964. Coated vesicles in the pericardial cells of the aphid (Myzuspersicae Sulz)Protoplasma 59, 351-367.

Brockhouse, A.C., Horner, H.T., Booth, T.F., Bonning, B.C., 1999. Pericardial cell ultrastructure in the tobacco hornworm Manduca sexta L. (Lepidoptera: Sphingidae)Int. J. Insect Morphol. Embryol. 28, 261-271.

Carmena, A., Gisselbrecht, S., Harrison, J., Jimenez, F., Michelson, A.M., 1998. Combinatorial signaling codes for the progressive determination of cell fates in the Drosophila embryonic mesodermGenes Dev. 12, 3910-3922.

Chagas, G.C., Caetano, F.H., 2003. Ultrastructure of the pericardial cells of the ant Camponotus rufipes (Hymenoptera: Formicidae). Acta Microsc. 12, 609-700.

Chen, Z., Zhu, J.-y., Fu, Y., Richman, A., Han, Z., 2016. Wnt4 is required for ostia development in the Drosophila heartDev. Biol. 413, 188-198.

Crossley, A.C., 1972. The ultrastructure and function of pericardial cells and other nephrocytes in an insect - Calliphora erythrocephala. Tissue Cell 4, 529-560.

Crossley, A.C., 1985. Nephrocytes and pericardial cells. In: Kerkut, G.A., Gilbert, L.I. (Eds.), Comprehensive Insect Physiology, Biochemistry, and Pharmacology.. Pergamon Press, Oxford, pp. 487-516.

Curtis, N.J., Ringo, J.M., Dowse, H.B., 1999. Morphology of the pupal heart, adult heart, and associated tissues in the fruit fly, Drosophila melanogaster. J. Morph. 240, 225-235.

Das, D., Aradhya, R., Ashoka, D., Inamdar, M., 2008. Macromolecular uptake in Drosophila pericardial cells requires rudhira function. Exp. Cell Res. 314, 1804-1810.

Das, D., Aradhya, R., Ashoka, D., Inamdar, M., 2008. Post-embryonic pericardial cells of Drosophila are required for overcoming toxic stress but not for cardiac function or adult development. Cell Tissue Res. 331, 565-570.

Das, D., Ashoka, D., Aradhya, R., Inamdar, M., 2008. Gene expression analysis in post-embryonic pericardial cells of Drosophila. Gene Expr. Patterns 8, 199-205.

Donoviel, D.B., Freed, D.D., Vogel, H., Potter, D.G., Hawkins, E., Barrish, J.P., Mathur, B.N., Turner, C.A., Geske, R., Montgomery, C.A., Starbuck, M., Brandt, M., Gupta, A., Ramirez-Solis, R., Zambrowicz, B.P., Powell, D.R., 2001. Proteinuria and perinatal lethality in mice lacking NEPH1, a novel protein with homology to NEPHRIN. Mol. Cell Biol. 21, 4829-4836.

Drechsler, M., Schmidt, A., Paululat, A., 2013. The conserved ADAMTS-like protein Lonely heart mediates matrix formation and cardiac tissue integrity. PLoS Gent. 9, e1003616.

Drysdale, R., the FlyBase, Consortium, 2008. FlyBase: a database for the drosophila research community. Methods Mol. Biol. 420, 45-59.

Fan, Y., Lu, H., Liang, W., Hu, W., Zhang, J., Chen, Y.E., 2017. Krüppel-like factors and vascular wall homeostasis. J. Mol. Cell Biol. 9, 352-363.

Fife, H.G., Reddy Palli, S., Locke, M., 1987. A function for pericardial cells in an insect. Insect Biochem. 17, 829-840.

Hamano, Y., Grunkemeyer, J.A., Sudhakar, A., Zeisberg, M., Cosgrove, D., Morello, R., Lee, B., Sugimoto, H., Kalluri, R., 2002. Determinants of vascular permeability in the kidney glomerulus. J. Biol. Chem. 277, 31154-31162.

Han, Z., Bodmer, R., 2003. Myogenic cells fates are antagonized by Notch only in asymmetric lineages of the Drosophila heart, with or without cell division. Development 130, 3039-3051.

Hartley, P.S., Motamedchaboki, K., Bodmer, R., Ocorr, K., 2016. SPARC-dependent cardiomyopathy in Drosophila. Circ. Cardiovac. Genet. 9, 119-129.

Helmstädter, M., Lüthy, K., Gödel, M., Simons, M., Ashish, Nihalani, D., Rensing, S.A., Fischbach, K.-F., Huber, T.B., 2012. Functional study of mammalian Neph proteins in Drosophila melanogaster. PLoS ONE 7, e40300.

Helmstädter, M., Simons, M., 2017. Using Drosophila nephrocytes in genetic kidney diseaseCell Tissue Res. 369, 119-126.

Hermle, T., Braun, D.A., Helmstädter, M., Huber, T.B., Hildebrandt, F., 2017. Modeling monogenic human nephrotic syndrome in the Drosophila garland cell nephrocyte.. J. Am. Soc. Nephrol. 28, 1521-1533.

Hollande, D.C., 1916. Le role physiologique des cellules pericardiales des insectes et leur coloration vitale par le carinate d'ammonique. Arch. Zool. 55, 67.

Hüsken, M., Hufnagel, K., Mende, K., Appel, E., Meyer, H., Peisker, H., Tögel, M., Wang, S., Wolff, J., Gorb, S.N., Paululat, A., 2015. Adhesive pad differentiation in Drosophila melanogaster depends on the Polycomb group gene Su(z)2. J. Exp. Biol. 218, $1159-1165$

Ivy, J.R., Drechsler, M., Catterson, J.H., Bodmer, R., Ocorr, K., Paululat, A., Hartley, P.S., 2015. Klf15 is critical for the development and differentiation of Drosophila nephrocytesPLoS ONE 10, e0134620.

Kambysellis, M.P., Wheeler, M.R., 1972. Banded polytene chromosomes in pericardial cells of Drosophila. J. Hered. 63, 214-215.

Kimbrell, D.A., Hice, C., Bolduc, C., Kleinhesselink, K., Beckingham, K., 2002. The Dorothy enhancer has Tinman binding sites and drives hopscotch-induced tumor formation. Genesis 34, 23-28.
Koenig, J.H., Ikeda, K., 1990. Transformational process of the endosomal compartment in nephrocytes of Drosophila melanogaster.. Cell Tissue Res. 262, 233-244.

Kosaka, T., Ikeda, K., 1983. Reversible blockage of membrane retrieval and endocytosis in the garland cell of the temperature-sensitive mutant of Drosophila melanogaster, Shibire-ts1. J. Cell Biol. 97, 499-507.

Lammers, K., Abeln, B., Hüsken, M., Lehmacher, C., Psathaki, O.E., Alcorta, E., Meyer, H., Paululat, A., 2017. Formation and function of intracardiac valve cells in the Drosophila heartJ. Exp. Biol. 220, 1852-1863.

Lehmacher, C., Abeln, B., Paululat, A., 2012. The ultrastructure of Drosophila heart cellsArthropod Struct. Dev. 41, 459-474.

Lehmacher, C., Tögel, M., Pass, G., Paululat, A., 2009. The Drosophila wing hearts consis of syncytial muscle cells that resemble adult somatic musclesArthropod Struct. Dev. 38, 111-123.

Lim, H.-Y., Wang, W., Chen, J., Ocorr, K., Bodmer, R., 2014. ROS regulate cardiac function via a distinct paracrine mechanism. Cell Rep. 7, 35-44.

Lőrincz, P, Lakatos, Z., Varga, Á, Maruzs, T., Simon-Vecsei, Z., Darula, Z., Benkô, P., Csordás, G., Lippai, M., Andó, I., Hegedűs, K., Medzihradszky, K.F., Takáts, S., Juhász, G., 2016. MiniCORVET is a Vps8-containing early endosomal tether in Drosophila. eLife 5, e14226.

Mandal, L., Banerjee, U., Hartenstein, V., 2004. Evidence for a fruit fly hemangioblast and similarities between lymph-gland hematopoiesis in fruit fly and mammal aorta-gonadal-mesonephros mesoderm. Nat. Genet. 36, 1019-1023.

Mills, R.P., King, R.C., 1965. The pericardial cells of Drosophila melanogaster. Q. J. microsc. Sci. 106, 261-268.

Molina, M.R., Cripps, R.M., 2001. Ostia, the inflow tracts of the Drosophila heart, develop from a genetically distinct subset of cardial cells. Mech. Dev. 109, 51-59.

Nagy, P., Varga, A., Kovacs, A.L., Takats, S., Juhasz, G., 2015. How and why to study autophagy in Drosophila: it's more than just a garbage chute. Methods 75, 151-161.

Nixon, R.A., 2007. Autophagy, amyloidogenesis and Alzheimer disease. J. Cell Sci. 120, 4081-4091.

Nogueira, N.F.S., SantosMallet, J.R., deSouza, W., 1995. Fine structure and cytochemistry of the dorsal vessel of Pan strongylus megistus (Burmeister, 1835) (Hemiptera: Reduviidae). Biocell 19, 229-242.

Palli, S.R., Locke, M., 1987. The synthesis of hemolymph proteins by the larval epider mis of an insect Calpodes ethlius (Lepidoptera, Hesperiidae). Insect Biochem. 17, 711-722.

Palli, S.R., Locke, M., 1987. Hemolymph protein synthesis by the larval midgut of an in sect Calpodes ethlius (Lepidoptera, Hesperiidae). Insect Biochem. 17, 561-572.

Palli, S.R., Locke, M., 1988. The synthesis of hemolymph proteins by the larval fat body of an insect Calpodes ethlius (Lepidoptera: Hesperiidae)Insect Biochem. 18, 405-413.

Pass, G., Tögel, M., Krenn, H., Paululat, A., 2015. The circulatory organs of insect wings: Prime examples for the origin of evolutionary novelties. Zool. Anz. 256, 82-95.

Pastor-Pareja, J.C., Xu, T., 2011. Shaping cells and organs in Drosophila by opposing roles of fat body-secreted collagen IV and perlecan. Dev. Cell. 21, 245-256.

Poiani, S.B., da Cruz-Landim, C., 2007. Histology and ultrastructure of pericardial cells of Scaptotrigonap ostica Latreille (Hymenoptera, Apidae) in workers and queens of different ages. Micron 38, 766-770.

Popichenko, D., Paululat, A., 2004. Cell fate decisions in the Drosophila dorsal vessel depend on the multiadapter protein Inscuteable. Genesis 40, 218-222.

Putaala, H., Soininen, R., Kilpelainen, P., Wartiovaara, J., Tryggvason, K., 2001. The murine nephrin gene is specifically expressed in kidney, brain and pancreas: inactivation of the gene leads to massive proteinuria and neonatal death. Hum. Mol. Genet. $10,1-8$

Rizki, T.M., 1978. The circulatory system and associated cells and tissues. In: Ashburner M, Wright, T.R.F. (Eds.), The Genetics and Biology of Drosophila. Academic Press, New York, NY, pp. 397-452.

Sanger, J.W., McCann, F.V., 1968. Fine structure of the pericardial cells of the moth, Hyalophora cecropia, and their role in protein uptake. J. Insect Physiol. 14, 1839-1845.

Sellin, J., Albrecht, S., Kölsch, V., Paululat, A., 2006. Dynamics of heart differentiation, visualized utilizing heart enhancer elements of the Drosophila melanogaster bHLH transcription factor hand. Gene Expr. Patterns 6, 360-375.

Shahrestani, P., Burke, M.K., Birse, R., Kezos, J.N., Ocorr, K., Mueller, L.D., Rose, M.R Bodmer, R., 2017. Experimental evolution and heart function in Drosophila. Physiol. Biochem. Zool. 90, 281-293.

Tepass, U., Hartenstein, V., 1994. The development of cellular junctions in the Drosophila embryo. Dev. Biol. 161, 563-596.

Tögel, M., Pass, G., Paululat, A., 2008. The Drosophila wing hearts originate from pericar dial cells and are essential for wing maturation. Dev. Biol. 318, 29-37.

Tögel, M., Pass, G., Paululat, A., 2013. In vivo imaging of Drosophila wing heart development during pupal stages. Int. J. Dev. Biol. 57, 13-24.

Tutor, A.S., Prieto-Sanchez, S., Ruiz-Gomez, M., 2014. Src64B phosphorylates Dumbfounded and regulates slit diaphragm dynamics: Drosophila as a model to study nephropathiesDevelopment 141, 367-376.

Ward, E.J., Skeath, J.B., 2000. Characterization of a novel subset of cardiac cells and their progenitors in the Drosophila embryoDevelopment 127, 4959-4969.

Wartiovaara, J., Ofverstedt, L.G., Khoshnoodi, J., Zhang, J.J., Makela, E., Sandin, S., Ruotsalainen, V., Cheng, R.H., Jalanko, H., Skoglund, U., Trygfgvason, K., 2004. Nephrin strands contribute to a porous slit diaphragm scaffold as revealed by electron tomography. J. Clin. Invest. 114, 1475-1483.

Weavers, H., Prieto-Sanchez, S., Grawe, F., Garcia-Lopez, A., Artero, R. Wilsch-Brauninger, M., Ruiz-Gomez, M., Skaer, H., Denholm, B., 2009. The insect nephrocyte is a podocyte-like cell with a filtration slit diaphragm. Nature 457 , 322-326.

Wilmes, A., Klinke, N., Rotstein, B., Meyer, H., Paululat, A., 2018. Assembly of the collagen iv-like protein pericardin is essential for heart integrity. Biol. Open(in press).

Zhang, F., Zhao, Y., Han, Z., 2013. An in vivo functional analysis system for renal gene discovery in Drosophila pericardial nephrocytesJ. Am. Soc. Nephrol. 24, 191-197.

Zhang, F., Zhao, Y.G., Chao, Y., Muir, K., Han, Z., 2013. Cubilin and amnionless mediate protein reabsorption in Drosophila nephrocytesJ. Am. Soc. Nephrol. 24, 209-216. 
Zhuang, S., Shao, H., Guo, F., Trimble, R., Pearce, E., Abmayr, S.M., 2009. Sns and Kirre, the Drosophila orthologs of Nephrin and Neph1, direct adhesion, fusion and formation of a slit diaphragm-like structure in insect nephrocytes.. Development 136, 2335-2344.
Zmojdzian, M., de Joussineau, S., Da Ponte, J.P., Jagla, K., 2018. Distinct subsets of Eve pericardial cells stabilise cardiac outflow and contribute to Hox-triggered heart morphogenesis in Drosophila. Development https://doi.org/10.1242/dev.158717. 